\title{
Endoscopic ultrasound-guided ethanol ablation of a symptomatic sporadic insulinoma
}

An insulinoma is an insulin-secreting neuroendocrine tumor (NET) which may lead to symptomatic fasting hypoglycemia. These often small lesions are primarily located in the pancreas. Endoscopic ultrasonography (EUS) has been found to be the optimal diagnostic modality for NET identification.

Surgical resection of the tumor is the mainstay of therapy for an insulinoma. However, for a small subset of patients, particularly those who are elderly with comorbidity, pancreatic surgery can be associated with high morbidity and mortality rates. It has been suggested that minimally invasive EUS-guided ablative treatment may be an attractive alternative therapy for these patients $[1,2]$.

An 82-year-old woman with a history of heart failure presented with symptomatic hypoglycemia (glucose $2.2 \mathrm{mmol} / \mathrm{L}$ ) and elevated levels of blood insulin (14 mIU/L) and C-peptide (1820 pmol/L). A computed tomography (CT) scan of the pancreas revealed no lesion. Linear-array EUS showed a round, well-demarcated, hypoechoic lesion of $9.5 \times 8.0 \mathrm{~mm}$ in the pancreatic body, near the confluence of the superior mesenteric and splenic veins ( $\mathbf{F i g} \mathbf{1}$ ). The results of cytological investigation using EUS-guided fine-needle aspiration (EUS-FNA) were compatible with a NET (๑ Fig. 2).

Surgical resection was considered to be associated with a high risk of complications. Instead, we decided to inject the lesion with $0.3 \mathrm{ml}$ of ethanol (96\%) under EUS guidance using a 25-gauge needle (EchoTip Ultra; Cook, Limerick, Ireland) through a linear-array echoendoscope (GF-UCT140-AL5; Olympus, Tokyo, Japan). The lesion became a whitish color during ethanol injection ( $\bullet$ Video 1 ).

Directly after the ethanol injection, blood glucose $(6.4 \mathrm{mmol} / \mathrm{L})$, insulin $(6 \mathrm{mIU} / \mathrm{L})$, and C-peptide (910 pmol/L) levels all normalized. No abdominal pain occurred, and serum amylase and lipase levels remained normal. After 2 months, EUS showed a decrease in the diameter of the lesion $(7.0 \times 5.5 \mathrm{~mm})$. The lesion appeared somewhat more hypoechoic than before, and the borders were less well demarcated $(\bullet$ Fig. 3). Over a period of 6 months,

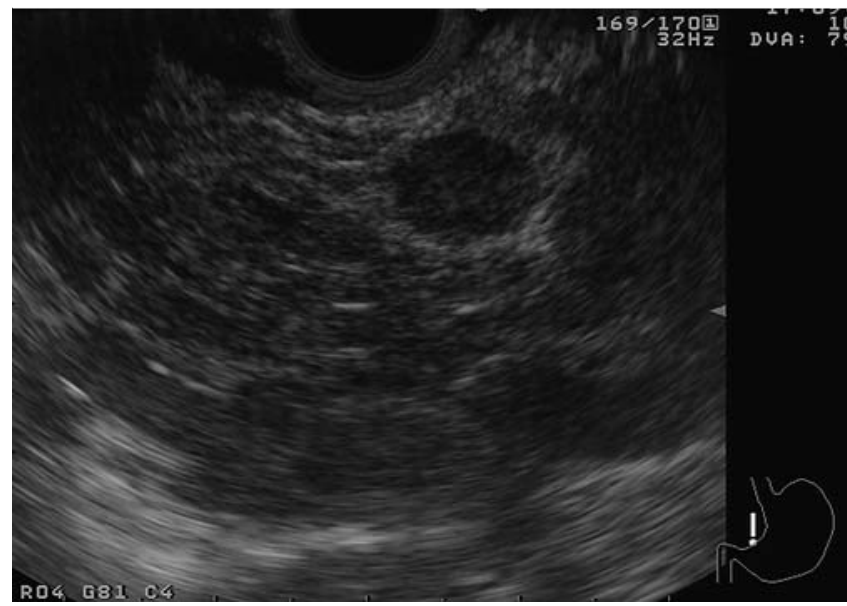

Fig. 1 A round, well-demarcated, hypoechoic lesion of $9.5 \times 8.0 \mathrm{~mm}$ in the pancreatic body, highly suggestive of a neuroendocrine tumor (NET).

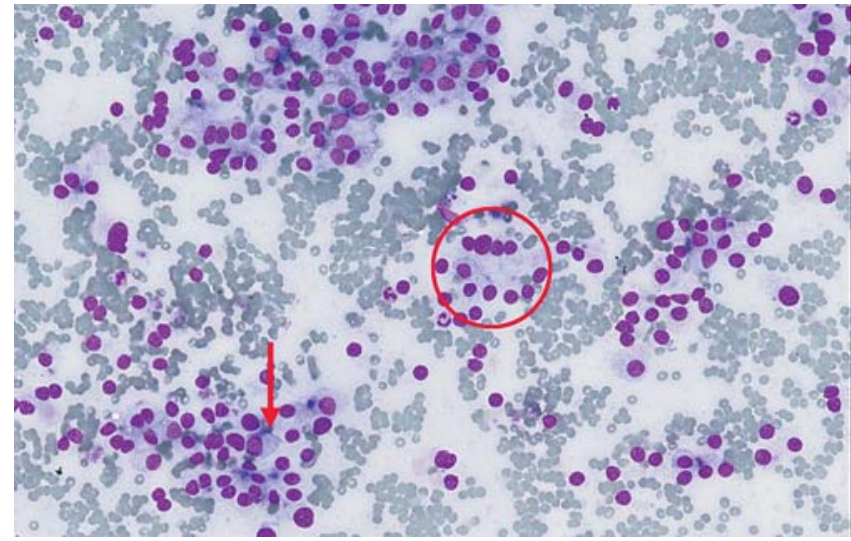

Fig. 2 Cytology smear after endoscopic ultrasonography-guided fine-needle aspiration (EUS-FNA), showing a cellular specimen composed of a loosely arranged monotonous cell population of plasmacytoid cells with eccentric nuclei (arrow) and formation of rosettes (circle), consistent with a neuroendocrine tumor (NET).

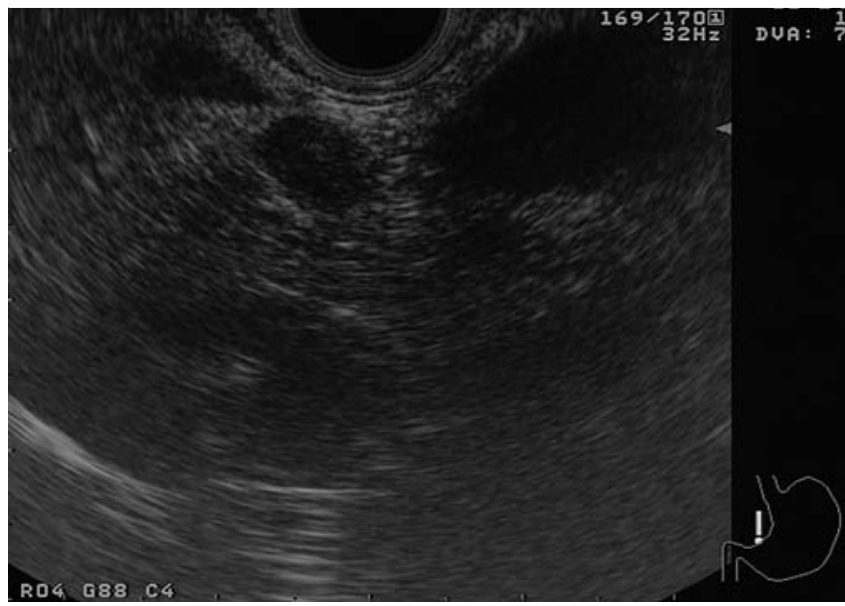

Fig. 3 The pancreatic lesion, 2 months after ethanol (96\%) ablation therapy. the patient remained without any symptoms of hypoglycemia.

\section{Endoscopy_UCTN_Code_TTT_1AS_2AD}

Competing interests: None 
F. P. Vleggaar ${ }^{1}$, E. A. bij de Vaate ${ }^{2}$, G. D. Valk ${ }^{3}$, R. J. Leguit ${ }^{4}$, P. D. Siersema ${ }^{1}$ 1 Department of Gastroenterology and Hepatology, University Medical Center Utrecht, The Netherlands

2 Department of Internal Medicine, Zuwe Hofpoort Ziekenhuis, Woerden, The Netherlands

3 Department of Internal Medicine, University Medical Center Utrecht, The Netherlands

4 Department of Pathology, University Medical Center Utrecht, The Netherlands

\section{References}

1 Jurgensen C, Schuppan D, Neser F et al. EUSguided alcohol ablation of an insulinoma. Gastrointest Endosc 2006; 63: 1059-1062

2 Deprez PH, Claessens A, Borbath I et al. Successful endoscopic ultrasound-guided ethanol ablation of a sporadic insulinoma. Acta Gastoenterol Belg 2008; 71: 333 - 337
Bibliography

DOI $10.1055 / \mathrm{s}-0030-1256775$

Endoscopy 2011; 43: E328 - E329

(c) Georg Thieme Verlag KG Stuttgart · New York . ISSN 0013-726X

\section{Corresponding author}

\section{F. P. Vleggaar, MD}

Department of Gastroenterology and Hepatology University Medical Center Utrecht

Heidelberglaan 100

Utrecht 3584 CX

The Netherlands

Fax: +31-88-7555533

f.vleggaar@umcutrecht.nl 